\title{
AS PESSOAS “PERIGOSAS” E “SUSPEITAS” E AS PESSOAS "CRIMINOSAS" NAS NORMATIVAS MIGRATÓRIAS BRASILEIRAS ${ }^{1}$
}

\section{THE "DANGEROUS” AND "SUSPECT" PEOPLE AND THE “CRIMINALS” ON BRAZILIAN MIGRATION NORMS}

\section{Lucia Sestokas}

luciasestokas@gmail.com

Mestranda do Programa de Pós-Graduação em Antropologia Social (PPGAS) da Universidade Estadual de Campinas (Unicamp)

ORCID: https://orcid.org/0000-0002-5771-9804

\section{RESUMO}

No presente artigo, desenvolvo argumentos iniciais sobre como os deslocamentos no Brasil são construídos e geridos a partir de noções de "pessoa perigosa" ou "pessoa suspeita", mas também a partir de "pessoa criminosa". Para tal, apresento um breve histórico de tais categorias nas normativas brasileiras, reavivadas pela publicação da Portaria 666 em 2019, assim como uma análise etnográfica da audiência criminal de uma pessoa não-brasileira processada por tráfico de drogas internacional em São Paulo. Pretendo assim trazer para o debate o papel de agentes e instâncias estatais na construção e operação de tais noções.

Palavras-chave: deslocamentos; justiça criminal; antropologia do estado.

\begin{abstract}
In the present article I develop initial arguments about how displacements in Brazil are constructed and managed from notions of "dangerous person" or "suspicious person", but also of "criminal person". To this end, I present a brief history of these categories in Brazilian norms, revived by the publication of the Ordinance 666 in 2019, as well as an ethnographic analysis of a criminal hearing of a non-Brazilian person prosecuted for international drug trafficking in São Paulo. Thus, I intend to bring to the debate the role of state agents and instances in the construction and operation of such notions.
\end{abstract}

Keywords: displacement; criminal justice; anthropology of the state.

\section{INTRODUÇÃO}

Quem eram eles? Uma pessoa tailandesa que tava no Brasil. Mas pediram pra você vir para o Brasil fazer o quê? A pessoa disse que eu ia trabalhar. Ela já tinha feito esse trabalho, só que não no Brasil, e não tinha acontecido nada. Por isso não achei que eram drogas. Mas o que a pessoa pediu pra pegar no Brasil? Ela me disse que era uma mala com perfumes e roupas. Mas não prometeram nenhum dinheiro? Eles dis- 
seram que eu primeiro precisaria completar o trabalho para depois receber o dinheiro. Quanto era? 120.000 em moeda tailandesa. Não sei quanto era em dólar, mas era muito dinheiro pra mim. Eles gastaram todo esse dinheiro em passagem e estadia e você achou que só tinha perfume e roupa na mala? Eu não pensei nisso, não achei que estava fazendo nada de errado até me chamarem para ver a mala. A senhora acha normal que gastem tanto para transportar roupas e perfumes que nem custam tudo isso? Eles não me falaram, eu não sabia que era drogas. Eu não teria vindo. Você não sabia que eram drogas, mas não achou que era algo ilegal como armas ou joias por causa de toda essa estrutura? Me instruíram para não abrir a mala para que eu fosse paga, então eu obedeci. Em algum momento suspeitou da mala? A insistência de não abrir a mala não despertou suspeitas? Eu falei com meus amigos sobre isso e me falaram para não abrir. Me falaram para não me preocupar. Se você estava trabalhando pra gente legal, de onde veio esse medo? Quando pensei nesse medo, pensei que tinha que tomar conta dos meus filhos e do meu pai, então não abri. Se era só roupa, qual seria o problema? Qual o medo? Eles disseram pra não abrir. Fiquei com suspeita e com medo, perguntei se tinha algo de ilegal e disseram que não. Mas aí eu já tinha passado várias noites aqui e só pensava em voltar para minhas crianças e meu pai. Aí você concluiu que tinha algo ilegal na mala? Sim. Por que a senhora não desistiu ou procurou a polícia para se livrar disso? Eu não sabia quem procurar para ajuda. Eles me chamaram e me colocaram num táxi para me levar no aeroporto. Mas no aeroporto você não podia falar com autoridades? Eu não sabia o que fazer e se eu falasse sobre drogas eu provavelmente seria presa. Eu com certeza seria presa (Trecho de caderno de campo).

O diálogo aqui descrito se deu durante uma audiência criminal entre o juiz e o promotor, que faziam as perguntas, e a ré, que as respondia. A conversa foi traduzida por duas intérpretes, uma do português para o inglês e outra do inglês para o tailandês. Nessa audiência, uma mulher tailandesa foi acusada, condenada e sentenciada por tráfico internacional de drogas. Venho assistindo a audiências de instrução e julgamento ${ }^{2}$ de pessoas não-brasileiras ${ }^{3}$ processadas criminalmente no Brasil como parte do trabalho etnográfico desenvolvido no mestrado 4 . No texto que aqui apresento, busco desenvolver argumentos iniciais sobre como os deslocamentos no Brasil são historicamente construídos e geridos a partir de noções de "pessoa perigosa" ou "pessoa suspeita", mas também a partir de "pessoa criminosa". Para isso, trago uma breve análise histórica das normativas brasileiras destinadas à regulação dos deslocamentos internacionais no Brasil, bem como uma análise etnográfica da audiência criminal acima mencionada. Pretendo assim trazer para o debate o papel de agentes e instâncias estatais na construção e operação de tais noções.

Reavivando debates acerca da seleção dos fluxos migratórios tidos como desejáveis e indesejáveis, a Portaria 666 do Ministério da Justiça (re)coloca as categorias de "pessoa perigosa" e "pessoa suspeita" na 
centralidade do controle dos fluxos migratórios no Brasil (BRASIL, 2019b). Publicada no Diário Oficial da União, em 26 de julho de 2019, a Portaria ${ }^{5}$ dispõe sobre o impedimento de ingresso, a repatriação e a deportação sumária de pessoa perigosa ou que tenha praticado ato contrário aos princípios e objetivos dispostos na Constituição Federal. Essa Portaria regula a aplicação do Estatuto do Refugiado, Lei 9.474, de 22 de julho de 1997 (BRASIL, 1997) e da Lei de Migração, Lei 13.445, de 24 de maio de 2017 (BRASIL, 2017b). A Portaria define como perigosa ou contrária à Constituição a pessoa que seja suspeita de envolvimento em terrorismo, grupo criminoso organizado ou associação criminosa armada, tráfico de drogas, pessoas ou armas de fogo, pornografia ou exploração sexual infanto-juvenil e torcida com histórico de violência em estádios. Define ainda que a pessoa em questão não poderá retornar ao país e fica sujeita à repatriação e deportação sumária, com até 48 horas para apresentar defesa.

As categorias de "pessoa perigosa" e "pessoa suspeita" não são novas. Ambas estão historicamente presentes nas normativas brasileiras, ainda que existam variações nas associações de tais categorias com grupos sociais específicos. Apresento aqui um breve histórico de tais categorias nas normativas, assim como algumas considerações acerca da associação destas com pessoas não-brasileiras processadas criminalmente no Brasil.

\section{PESSOAS “SUSPEITAS" E "PERIGOSAS": UM BREVE PANORAMA DAS NORMATIVAS BRASILEIRAS}

Para melhor analisar a construção das ideias de "pessoa perigosa" e "pessoa suspeita", vale olhar para os dispositivos legais adotados pelo Brasil desde o período colonial, assim como para seus contextos históricos. É sintomática a forma como alguns temas são abordados em tais dispositivos, tais como as medidas de retirada compulsória ${ }^{6}$, as razões de impedimento de ingresso, as condições de denegação de vistos e residência e o tratamento dispensado para pessoas em conflito com a lei ${ }^{7}$, como será apontado a seguir.

Analisando a construção da categoria "imigrante" no Brasil, Giralda Seyferth traça uma historicização de normativas que regulam a imigração no Brasil. A autora aponta como a eugenia aparece em atos legais ao longo do século XX (SEYFERTH, 2008). A imigração é vista como possibilidade ligada ao "aperfeiçoamento das gerações futuras e a higiene e saúde", que deve "ser olhada sob o ponto de vista dos interesses da raça

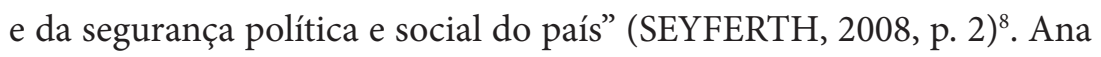
Luisa Zago de Moraes mostra ainda que, entre os séculos XIX e XX, colonos europeus mesmo que considerados desejáveis eram controlados, "através da indução do deslocamento dirigido a determinados locais e a realização de específicas práticas produtivas e políticas" (MORAES, 
2016, p. 43), ou tutelados, funcionando "como mecanismo de controle sobre um conjunto de indivíduos potencialmente perigosos em razão de seus comportamentos desviantes" (MORAES, 2016, p. 43). É no século $\mathrm{XX}$ que, aponta a autora, "houve a mudança do paradigma do colono-imigrante para o do anarquista-estrangeiro" (MORAES, 2016, p. 52).

Em $1890^{9}$ é promulgado o Decreto ${ }^{10} 528^{11}$, que libera a entrada de "indivíduos válidos e aptos e não sujeitos à ação criminal no seu país, excetuando os nativos da Ásia e da África ${ }^{12}$, os mendigos e os indigentes" (SEYFERTH, 2008, p. 11). Nos Decretos 6.455, de $1907^{13}$ e no Decreto 9.081, de $1911^{14}$, que regulamentam o Serviço de Povoamento do Solo Nacional, restringem o acolhimento de imigrantes àqueles "menores de 60 anos que, não sofrendo de doenças contagiosas, não exercendo profissão ilícita, nem sendo reconhecidos como criminosos, desordeiros, mendigos, vagabundos, dementes, ou inválidos, chegarem aos portos nacionais com passagem de terceira classe" (SEYFERTH, 2008, p. 12).

É somente em 1921, através do Decreto $4.247^{15}$, versando sobre a regulação de entrada e saída de estrangeiros no território nacional, que as condições de expulsão de indesejáveis serão detalhadas, com enfoque naqueles "que foram banidos ou expulsos de outro país" (SEYFERTH 2008, p. 13). Seyferth aponta ainda que decretos da década de 1930 não só mantiveram os dispositivos criados até então como "incluíram ciganos, prostitutas e nômades entre os indesejáveis; e, vagamente, mencionavam 'razões político-sociais' para recusar o visto de entrada" (SEYFERTH, 2008, p. 14). Nesse contexto é promulgado o Decreto 4.743 , de $1923^{16}$, que prevê administrativamente a expulsão de estrangeiros no caso dos crimes de conspiração (MORAES, 2016, p. 54). Moraes descreve a participação do então deputado Adolpho Gordo na associação entre o anarquismo, o estrangeiro e o indesejável. Defendia em seus discursos um enrijecimento das normas de expulsão e o aumento de repressão de estrangeiros, que considerava elementos nocivos perturbadores da vida normal, fomentadores de greves e desordens (MORAES, 2016, p. 55).

Moraes, que analisa a relação entre política criminal e política migratória no Brasil, debruça-se sobre o uso da expulsão ao longo da história do Brasil. A autora mostra como, durante a República Velha, eram entendidos como direitos soberanos do Estado a expulsão independentemente de processo e condenação judicial e a não-admissão quando fosse considerada conveniente (MORAES, 2016, p. 58). Na primeira metade do século XX, mais especificamente em 1924 acontece a Conferência de Emigração e Imigração, que insere a "questão humanitária" na questão migratória (MORAES, 2016, p. 59). Como aponta Moraes, o embaixador brasileiro Carlos Martins definiu a motivação da Conferência pela preocupação dos países europeus "com a diminuição do escoamento do excesso de sua população, devido à diminuição da emigração transoceânica, muito em razão do crescimento da importância da categoria dos 
indesejáveis" (MORAES, 2016, p. 59). Nesse contexto, o Brasil não concordou com as conclusões da Conferência, que compreendeu como um ganho dos países europeus, emigrantistas, sobre os países imigrantistas.

É com o governo de Getúlio Vargas, a seguir, que a política migratória brasileira passa a ser mais restritiva, sob a justificativa de priorizar o trabalhador nacional. A expulsão do estrangeiro indesejável acompanha o tom político da época, de maior controle dos fluxos migratórios. Foi no Decreto-Lei ${ }^{17}$ 406, de $1938^{18}$ que ocorreu a inclusão do critério "gente nociva à ordem pública e à segurança nacional" para justificar o impedimento de ingresso ao país (SEYFERTH, 2008, p. 14). Como coloca Seyferth, ainda que a imigração fosse necessária para o povoamento do território e para o emprego da mão de obra, ela não podia ser liberada, sendo o entendimento da época que o "alienígena deve estar sob controle do estado” (SEYFERTH, 2008, p. 16).

Adentrando o período da ditadura civil-militar brasileira, Marcia Sprandel apresenta um panorama das normativas que regulam a migração no Brasil (SPRANDEL, 2015). Desde 1969, aponta a autora, as normativas brasileiras regulam a expulsão com base em alguns critérios. O Decreto Lei $417^{19}$, daquele ano, permite a expulsão do estrangeiro que atente contra a segurança nacional, a ordem política ou social, a tranquilidade e moralidade públicas e a economia popular, ou cujo procedimento o torne nocivo ou perigoso à conveniência ou aos interesses nacionais (SPRANDEL, 2015, p. 151). O Decreto Lei 941 determina ainda que não se concederá visto ao estrangeiro "nocivo à ordem pública" (BRASIL, 1969).

$\mathrm{Na}$ Lei 6.815 , de $1980^{20}$, aprovada durante a ditadura civil-militar brasileira e durante o período da Guerra Fria, "a ameaça que vem de fora é pensada como intrinsecamente ligada aos 'inimigos internos', os brasileiros considerados 'subversivos"' (SPRANDEL, 2015, p. 146). Aqui, tanto a pessoa estrangeira quanto a pessoa brasileira subversiva são consideradas como ameaçadoras para o regime e para a "segurança nacional”. Buscando conceituar a ideia de segurança nacional, a autora traz a Lei de Segurança Nacional - Decreto-Lei 314 (BRASIL, 1967). Neste, a autora aponta a presença da palavra "estrangeiros" concentrada no capítulo "Dos crimes e das penas", aludindo à pessoa estrangeira, à organização estrangeira, ao governo estrangeiro e ao fundo estrangeiro como ameaças e propondo penas de reclusão como punição em casos de atos contra o Brasil. Cabe ressaltar que nesta lei não havia nenhuma previsão de visto ou residência para pessoas em cumprimento de pena fora da prisão no Brasil e era vetada a possibilidade de visto para quem fosse anteriormente expulso do País, salvo se a expulsão tiver sido revogada. Contudo, não se procedia à expulsão e tinha acesso à regularização migratória "o estrangeiro" que tivesse cônjuge brasileiro, com casamento celebrado há mais de cinco anos, ou que tivesse filho brasileiro. 
Foi somente em 2014 que, através de Resolução do Conselho Nacional de Imigração, posteriormente regulamentada pela Portaria da Secretaria Nacional de Justiça, "estrangeiros em cumprimento de pena no Brasil" poderiam, em virtude de decisão judicial, ter acesso à permanência provisória. A permanência era válida pelo período de cumprimento de pena e não anulava a expulsão. Vale ressaltar que ficava registrado no protocolo ${ }^{21}$ o tipo de pedido de visto solicitado, o que significa que constava nesse documento que a pessoa portadora estava em cumprimento de pena.

A atualmente vigente Lei de Migração, lei que dispõe sobre os direitos e os deveres do migrante e do visitante, regula a sua entrada e estada no País a partir de 2017 (BRASIL, 2017b). A lei define que é possível autorizar residência ao imigrante, ao residente fronteiriço ou ao visitante que esteja em liberdade provisória ou em cumprimento de pena no Brasil, ainda que vete a autorização de residência para pessoa condenada criminalmente no Brasil ou no exterior por sentença transitada em julgado, salvo em casos de infração de menor potencial ofensivo, de pedido de residência por motivos de tratamento de saúde, acolhida humanitária e reunião familiar ou caso a pessoa seja beneficiária de tratado em matéria de residência e livre circulação. O texto prevê ainda o cancelamento da expulsão, que ocorre nos casos de condenação com sentença transitada em julgado por crime de genocídio, crime contra a humanidade, crime de guerra, crime de agressão, crime comum doloso passível de pena privativa de liberdade, consideradas a gravidade e as possibilidades de ressocialização em território nacional. A medida, por outro lado, é vetada nos casos em que o expulsando tiver filho brasileiro que esteja sob sua guarda ou dependência econômica ou socioafetiva ou tiver pessoa brasileira sob sua tutela, tiver cônjuge ou companheiro residente no Brasil, sem discriminação alguma, reconhecido judicial ou legalmente, tiver ingressado no Brasil até os doze anos de idade, residindo desde então no país, ou for pessoa com mais de setenta anos que resida no País há mais de dez anos, considerados a gravidade e o fundamento da expulsão.

A gestão que então ocupava a Presidência da República após o impeachment da Presidenta Dilma Rousseff vetou, no ato de aprovação da lei, 18 trechos do texto originalmente apresentado ${ }^{22}$. A Regulamentação da mesma lei, adotada pelo Decreto 9.199, de 201723, deu continuidade às restrições impostas pelos vetos (BRASIL, 2017a). O documento Carta Aberta sobre o Processo de Participação Social na Regulamentação da Lei 13.455/17 e Pontos Preocupantes na Minuta do Decreto da nova Lei de Migração ${ }^{24}$, elaborado por organizações da sociedade civil, organismos internacionais, acadêmicas/os, imigrantes e refugiadas/os, indica alguns pontos centrais de preocupação com relação ao decreto. Como aponta o documento, a regulamentação mantém a utilização de termos amplos como "atos contrários aos princípios e objetivos consti- 
tucionais", mantém restritas as possibilidades de revogação de expulsão, contradizendo a garantia de não criminalização de migrantes por sua condição migratória pela lei e prevendo a prisão de migrantes devido à sua condição migratória, dentre outros.

Após a publicação da Portaria 666, a então procuradora-geral da República ${ }^{25}$ ajuizou a Arguição de Descumprimento de Preceito Fundamental contra a Portaria 666 (BRASIL, 2020). A ADPF apontou o conteúdo da Portaria como inconstitucional, baseando seu argumento na contrariedade da Portaria ao princípio da dignidade humana e no seu caráter violador dos preceitos fundamentais da legalidade, igualdade, ampla defesa, contraditório, devido processo legal e presunção de inocência. Argumenta que o uso do termo "pessoa perigosa" é discricionário, já que não requer provas, presença de materialidade ou indício de autoria. Oferece, então, "grave ofensa à ampla defesa e ao contraditório (...), pois o estrangeiro não terá como refutar uma acusação formal e embasada em determinadas provas" (BRASIL, 2020). O uso do termo "suspeita", por sua vez, é entendido como violador do princípio da legalidade e da presunção de inocência, já que não se trata necessariamente de atos condenados ou tampouco de atos efetivamente praticados, impossibilitando qualquer defesa por parte da pessoa acusada. $\mathrm{O}$ documento reforça que uma pessoa só pode ser considerada culpada pela prática de determinado delito após o trânsito em julgado de sentença penal condenatória.

A Portaria 666 (BRASIL, 2019b) mostra seu caráter violador pela discricionariedade com a qual atribui as características de "suspeita" e "perigosa" às pessoas estrangeiras, contribuindo para uma associação entre elas. Essa atribuição é feita sem necessariamente haver delito praticado, apresentação de provas ou possibilidade de defesa sobre a acusação. O devido processo legal, garantido pela Constituição brasileira assim como por inúmeras normativas internacionais ${ }^{26}$, ao contrário, estabelece que não pode haver restrição de direitos sem antes haver a instauração de um processo. Este processo deve ser adequado e guardar a igualdade entre as partes, o contraditório e a ampla defesa. No caso de processos criminais, a uma pessoa que é condenada por cometer um crime após o devido processo legal, é atribuída a categoria de "criminosa".

Cabe, então, analisar a atribuição da categoria "criminosa", o que inclui examinar o próprio funcionamento dos processos que a atribuem e a atuação de agentes e instâncias estatais que os operam. Para trazer elementos a estes questionamentos, apresento no próximo tópico dados bibliográficos e etnográficos sobre pessoas não-brasileiras em conflito com a lei no Brasil, submetidas, ao longo do processo criminal, ao chamado devido processo legal e todas as garantias que o cercam. 


\section{CONSIDERAÇÕES ACERCA DE PESSOAS NÃO-BRASILEIRAS PROCESSADAS CRIMINALMENTE NO BRASIL}

Inicialmente, trago aqui algumas considerações acerca da situação de pessoas não-brasileiras processadas criminalmente no Brasil. Pessoas não-brasileiras que cometeram um crime e foram sentenciadas no Brasil têm acesso mais limitado à regularização migratória e, via de regra, são submetidas a um processo administrativo de expulsão. Aquelas que já viviam no Brasil antes de serem condenadas podem ter seu documento brasileiro revogado e aquelas que têm antecedentes penais no Brasil e decidem permanecer no país têm maiores limites para acessar uma condição migratória regular, que, no caso delas, implica acessar a regularização migratória e revogar sua expulsão ${ }^{27}$. Nesse último caso, como aponta Natália Corazza Padovani em sua tese de doutorado, "os trânsitos decorrentes do comércio de drogas podem não estar diretamente relacionados a uma intencionalidade em migrar, mas a prisão e o tempo da pena abrem possibilidades e perspectivas migratórias" (PADOVANI, 2015, p. 126).

As pessoas em conflito com a lei, contudo, não constituem uma categoria uniforme: no processo criminal, para além de condenada ou absolvida, a pessoa pode ser considerada como "perigosa", ou "parte do crime organizado", em contraste com "de menor potencial ofensivo", "vítima de grupo criminoso", "traficada", "mula", etc. A forma como se é considerada no processo criminal tem impacto não só no andamento do processo criminal mas também no processo migratório, podendo influenciar no acesso à regularização migratória e na possibilidade de revogação ou não da expulsão.

Retomando o diálogo que abre este artigo, a audiência retratada se passou na $19^{a}$ Subseção Judiciária do Estado de São Paulo, conhecida como fórum federal de Guarulhos, em 2018. A importância do referido fórum se dá por ser nele onde ocorrem os julgamentos das prisões por tráfico internacional efetuadas no Aeroporto Internacional de Guarulhos (AIG). O Aeroporto Governador André Franco Montoro, de Guarulhos, é o maior aeroporto internacional do país e nele ocorre um número significativo das prisões de pessoas não-brasileiras no Brasil. Como mostra o estudo sobre tráfico internacional de drogas no AIG, feito pela defensora pública federal Érica de Oliveira Hartmann e pelos juízes federais Guilherme Roman Borges e Jorge Alberto Araújo de Araújo, o aeroporto é considerado como "a principal e mais relevante porta de entrada e saída aérea dos entorpecentes no território nacional” (HARTMANN, 2016, p. 4). Não à toa, o Infopen de junho de 2017 mostra que o estado de São Paulo comporta 1.421 "estrangeiros" privados de liberdade, representando o estado brasileiro com o maior número absoluto (mais de 65\% do número nacional) de "estrangeiros" presos (BRASIL, 2017c). 
$\mathrm{Na}$ audiência foram testemunhas um agente da Polícia Federal da Delegacia do Aeroporto de Guarulhos e um técnico de raio-X do mesmo local, que testemunharam terem participado da prisão em flagrante da ré depois que observaram pelo raio- $\mathrm{X}$ a presença de massa orgânica em sua mala. Ambos alegaram que, apesar de ela concordar que a mala era dela, ela "parecia não entender a gravidade da situação" e "demonstrou surpresa" quando encontraram pasta de cocaína em sua mala. Ambos testemunharam que ela "colaborou o tempo todo".

A expertise policial aparece nas falas das testemunhas e constitui parte importante do processo criminal, assim como parte importante nas categorizações das pessoas que passam por tais agentes. Bruna Bumachar aponta em sua tese doutoral que é comum a prática de denúncias anônimas à Polícia Federal e que, além das denúncias, “esses policiais acumulam um corpo de saberes relacionado à vigilância de mobilidades" (BUMACHAR, 2016, p. 87). Os policiais aprendem, seja em treinamentos ou pela prática do trabalho, a "identificar suspeitas(os) a partir dos sinais deixados pelas performances destas(es) - no jeito de andar (especialmente quando a droga está envolta nas pernas ou no abdômen), no estado de tensão, no tipo de mala, no trajeto da viagem e assim por diante" (BUMACHAR, 2016, p. 87). Os autores Donnan Hastings e Wilson Thomas, ao descreverem a fala de um oficial da fronteira entre os EUA e o México, mostram como este justifica a execução de revistas corporais em algumas pessoas que atravessam a fronteira pela sua "intuição" ou "experiência adquirida no trabalho" (HASTINGS; THOMAS 1999, p. 129). Parecem ser os próprios corpos que atravessam a fronteira que oferecem as pistas, apontam os autores, mencionando a importância dada a "movimentos de olhos furtivos, mãos suadas e rosto ruborizado". Um guarda, por exemplo, afirma que acredita ser capaz de identificar contrabandistas "olhando em seus olhos" (HASTINGS; THOMAS, 1999, p. 131).

Após as manifestações iniciais do juiz e das perguntas feitas pelo promotor, o juiz pede para retomar as perguntas feitas até o momento: "A versão da senhora é que a senhora foi contratada para um trabalho inocente de transporte de roupas, mesmo eles falando que não podia falar pra ninguém e não podia abrir a mala. Você realmente acreditou que era algo inocente?". Nesse ponto, a ré começa a chorar efusivamente, mas responde: "Sim, foi exatamente isso". É nesse momento que a palavra é dirigida para a defesa, na figura do defensor da Defensoria Pública da União. Como de praxe, o defensor pergunta se a ré tem filhos, ao que ela responde que sim. "As crianças são economicamente dependentes de você?". O choro da ré continua quando ela responde que sim e que ela também toma conta de seu pai, que não pode trabalhar por ter problemas respiratórios. Ela diz que não tem mais ninguém. Antes da conclusão, o juiz pergunta se a ré gostaria de dizer mais alguma coisa. Ela responde: "Me desculpe por ter feito uma coisa errada. Eu só quero 
ir pra casa. Minha família é pobre. Eu tenho o dever de cuidar deles". "É só?" "É só". Nesse ponto, o juiz pede para o microfone da ré ser desligado por causa do barulho de choro.

O promotor compreendeu que "a circunstância indica com segurança necessária que a ré tinha consciência de que trazia drogas consigo. Embora acreditasse que o trabalho era lícito, ela sabia que o trabalho tinha potencialidade de ter algo ilícito por trás como verdadeiro motivo". Ele prossegue: "Quem aceita esse tipo de empreitada deve saber desse risco, está assentindo a esse risco". E conclui ainda que "como foi aliciada num terceiro país, aqui conheceu outras pessoas, fica certo que integrava organização criminosa”. Através da figura do promotor, o Ministério Público Federal move por condenação por tráfico internacional sem que seja concedida a confissão, já que a ré disse não saber da droga. Diz ainda que ter filhos menores "por si só" não implica na concessão de prisão domiciliar, pois nesse caso os filhos não estão no Brasil e, se estão sob cuidados de outra pessoa, a ré não é imprescindível ${ }^{28}$. A defesa, por sua vez, argumenta que a ré não tinha conhecimento da droga e que as testemunhas atestaram esse argumento. Sendo a ré primária, sem nunca antes ter viajado, o defensor concluiu que a ré foi usada por uma organização, mas não a integrou e não tem vínculo associativo estável com ela. "Foi usada como meio uma única vez para transporte".

Antes do fechamento da sentença, tanto o juiz quanto o promotor saem da sala. As pessoas que ficam na sala passam a conversar entre si. Comentam que "A gente sabe quem controla o tráfico aqui e ela foi bem orientada. Nesse caso não tem nenhum nigeriano na jogada”. "Ah! mas no backstage vai ter, sem dúvida alguma. Sempre tem”. Natália Padovani descreve em sua tese doutoral que "aos "africanos", mas principalmente, aos "nigerianos", são atreladas marcações de 'perigo' e 'poder"” (PADOVANI, 2015, p. 311). A autora aponta que a construção de uma ligação entre nigerianos e a rede de mercado transnacional de drogas está fortemente calcada em um viés racial. Bruna Bumachar descreve ainda que os chamados traficantes são descritos no masculino e com frequência denominados nigerianos. A autora aponta que no decorrer de sua pesquisa notou que o termo "nigeriano" é "comumente utilizado para se referir à coletividade de homens negros, em geral, africanos, mas não necessariamente nascidos ou oriundos da Nigéria, que mobilizam essa nacionalidade como tática para o recrutamento de mulas" (BUMACHAR, 2016, p. 73).

Retornando à sala, o juiz declara a ré culpada e a sentencia a uma pena de 4 anos, 10 meses e 10 dias, com regime inicial semiaberto. $\mathrm{O}$ juiz questiona se a ré tem alguma pergunta, ao que ela questiona se ficará na prisão por todo esse tempo. O juiz responde que não, que há progressão de regime para o semiaberto. Ela então pergunta o que é regime semiaberto e o juiz responde que é poder trabalhar de dia e voltar para a prisão de noite. $\mathrm{O}$ juiz pergunta para o escrivão se há progressão 
de regime em outros países. Ele responde que "tem progressão pra pena de morte, né, já sai pra uma instância superior”, ao que todos, com a exceção da ré, riem. Como de praxe, o juiz pergunta se a ré tem interesse em recorrer, ao que ela pergunta o que significa recorrer. Todos riem nesse momento e o juiz responde que significa pedir para diminuir a pena, mas que no caso dela essa pena já é mínima, então corre risco de aumentar. Ela diz que gostaria do conselho do defensor, que responde que "melhor não porque até que o tribunal recorra ela já progrediu de regime e está fora da prisão. E também se não recorre a expulsão sai antes", ao que ela então conclui assim: "tá, então eu não quero apelar". As frases finais da audiência, proferidas pelo juiz, foram: "Então tá bom, trânsito em julgado e tá pronto. Vamos assinar e vamos almoçar".

Como apontam Adriana Vianna e Laura Lowenkron, a ideia de Estado "deve ser pensada em sua carnadura, seus qualificativos morais, sua capacidade de moldar, limitar e produzir desejos e horizontes de possibilidade" (VIANNA; LOWENKRON, 2017, p. 19). Analisando como gênero e Estado se fazem mutuamente, as autoras consideram que ambos "se fazem em ato", sendo necessário para tal compreender "seus efeitos performativos, performances e materialidades contextualmente situados" (VIANNA; LOWENKRON, 2017, p. 19). Estado, então, se afasta de uma ideia imaterial, mas se faz nas ações de agentes e instâncias que o compõe.

Se "discricionariedade" é característica vinculada ao uso de categorias como "suspeita" ou "perigosa", vale questionar se o uso de "criminosa" ou "parte do crime organizado" que aparece nos processos criminais é, ao contrário, isento de discricionariedade. Vale também pontuar que "discricionariedade" não surge aqui no sentido de ineficiência dos agentes estatais que operam tais categorias, tampouco para defender que agentes estatais categorizam "mal" as pessoas em questão. O questionamento surge no sentido de chamar a atenção para como tais categorias são operadas por agentes do estado de formas diferenciadas, a depender tanto dos corpos que são categorizados quanto dos agentes que categorizam.

\section{CONCLUSÃO}

A Portaria 666 foi revogada ${ }^{29}$ por um novo dispositivo, a Portaria 770. Publicada em 11 de outubro de 2019, ela dispõe sobre o mesmo tema que a anterior, mas aumenta para cinco dias o prazo para defesa ou recurso da "pessoa sobre quem recaia a medida de deportação", incluindo também a notificação à Defensoria Pública da União. Além de retirar o termo "deportação sumária", prevê que "ninguém será impedido de ingressar no País, repatriado ou deportado por motivo de raça, religião, nacionalidade, grupo social ou opinião política", tampouco será impedido o ingresso ou submetida à repatriação ou à deportação "a pessoa 
perseguida no exterior por crime puramente político ou de opinião" ou "quando subsistirem razões para acreditar que a medida poderá colocar em risco a vida ou a integridade pessoal" (BRASIL, 2019c). Dentre outros pontos, mantém a definição de "pessoa perigosa" ou que tenha praticado ato contrário aos princípios e objetivos dispostos na Constituição Federal aquela sobre a qual recaem razões sérias que indiquem envolvimento em

terrorismo, grupo criminoso organizado, tráfico de drogas, pessoas ou armas de fogo, pornografia ou exploração sexual infanto-juvenil. Essas hipóteses serão reconhecidas e avaliadas pela autoridade migratória por meio de difusão ou informação oficial em ação de cooperação internacional, [...] lista de restrições estabelecida em ordem judicial ou em compromisso assumido pela República Federativa do Brasil perante organismo internacional ou Estado estrangeiro, [...] informação de inteligência proveniente de autoridade brasileira ou estrangeira, [...] investigação criminal em curso, e [...] sentença penal condenatória (BRASIL, 2019c).

Busco na noção de "regimes de mobilidade", de Nina Glick Schiller e Noel B. Salazar (2012), a possibilidade de pensar relações entre os movimentos privilegiados de algumas pessoas e os movimentos, migrações e interconexões proibidos, estigmatizados e codependentes de outras. Como colocam Glick Schiller e Salazar, $(2012$, p. 6) "é o trabalho daquelas pessoas cujos movimentos são considerados ilícitos e subversivos que possibilita a mobilidade fácil daquelas que parecem viver em um mundo sem fronteiras de riqueza e poder". A autora e o autor defendem que estudos sobre mobilidade devem poder normalizar uma forma de mobilidade sem, contudo, minimizar a importância do status legal e das categorias de racialização na facilidade da viagem e no ganho ou perda de status desse viajante (GLICK SCHILLER; SALAZAR, 2012, p. 6).

Retomando o trabalho de Hastings e Thomas (1999), os autores se debruçam sobre como corpos que carregam doenças são interpelados no atravessamento de fronteiras. Apontam, por exemplo, como os corpos destas pessoas são reduzidos a "disseminadores de doenças" (HASTINGS; THOMAS, 1999, p. 134) e, em um processo de desumanização, se tornam somente vírus e bactérias. Entendidos como elementos poluidores, são abordados por vários mecanismos para impedir sua propagação. Um corpo que carrega drogas é por vezes reduzido à conotação de ilicitude conferida à substância que carrega pelas instituições que o interpelam. Este corpo, então, é entendido como corpo a ser impedido, barrado nas fronteiras por onde passa. Pradeep Jeganathan (2018, p. 403) propõe que a suspeita sobre alguém que constitui a razão de ser do aparato do checkpoint, espaço de manifestação de uma fronteira. Os corpos permanecem sob supervisão, sendo que sua própria mobilidade faz com que as fronteiras militarizadas proliferem. 
Aqui é interessante atentar para os processos de categorização que diferenciam os movimentos das pessoas através dos territórios e das fronteiras. Em sua tese doutoral, Angela Facundo (2014) se debruçou sobre práticas e políticas de gerenciamento das populações refugiadas no Brasil. Analisando o processo de refúgio por elegibilidade no caso dos nacionais colombianos, a autora mostra como vai sendo produzida a categoria de "refugiado" 30 . A figura do "refugiado puro" se distancia de "migrantes que vão e voltam, viajantes desejosos de fortuna, perseguidos que não recorrem ao novo Estado para sua proteção, deslocados por catástrofes naturais, ameaçados pouco convincentes em sua narrativa, analfabetos burocráticos etc., considerados "anormalidades contaminantes” do refúgio (FACUNDO, 2014, p. 26). A prática da categorização operada por agentes do Estado vai construindo as categorias, constem elas em normativas ou não.

Marcia Sprandel ressalta como as construções dos textos legais "são marcadas por circunstâncias e subjetividades” (2015, p. 146). A autora aponta ainda que a associação entre migração e crime tem relação direta com a formação do Estado-nacional moderno. Ainda assim, a partir de 1980, "a criminalização das migrações passou a ganhar concretude e prioridade na agenda política de países hegemônicos" (SPRANDEL, 2015, p. 165), usando elementos penais e criminais para tratar questões sociais. Fica evidente a recorrência do uso de termos como "segurança nacional", "pessoa nociva", "atividade criminosa", "pessoa suspeita", ainda que o que se é entendido por cada um desses termos varia no tempo, de acordo com as instituições envolvidas, etc. ${ }^{31}$

O que nos mostram as normativas aqui abordadas é que as construções de categorias andam juntas: só existe a possibilidade de deslocamento de algumas pessoas porque existe a vigilância, controle e limitações dos deslocamentos de outras. As noções de "pessoa perigosa", "pessoa suspeita" e "pessoa criminosa" mostram ainda que as categorias judiciais e migratórias presentes nas normativas e nas audiências criminais são construídas no fazer cotidiano de agentes e instâncias de diferentes aparelhos de Estado. A atribuição dessas noções não acontece igualmente a qualquer corpo, mas se faz por atributos de gênero, raça, classe e nacionalidade. Essas noções constituem assim elementos de gestão dos deslocamentos, ao passo que delineiam aquelas que podem ou não se deslocar, que se deslocam com maior ou menor facilidade e cujo deslocamento é considerado legítimo ou mesmo legal.

\section{NOTAS}

1. O presente texto é fruto de apresentações feitas no $43^{\circ}$ Encontro Anual da Anpocs - SPG 18: Migrações e a produção de fronteiras e no Workshop Gênero, interseccionalidades e mobilidades - GT Mobilidades, Estado, territorialidades, organizado por Natália Padovani, a quem agradeço pelas considerações. Sou 
também muito grata pela revisão e sugestões de Letizia Patriarca ao texto que aqui apresento.

2. Audiências de instrução e julgamento são atos processuais em que as partes oferecem seus depoimentos, incluindo os peritos e as testemunhas, produzindo provas orais. A sessão é presidida por um(a) juiz(a) e conta com a participação das partes e advogadas(os). No caso de audiências criminais por tráfico de drogas, é o Ministério Público, representado pelo(a) promotor(a), que oferece as denúncias contra $\mathrm{a}(\mathrm{o})$ ré(u), já que o tráfico de drogas é um crime contra a saúde pública.

3. Utilizo aqui o termo "não-brasileiras" para buscar algum distanciamento dos termos que aparecem nos campos que aqui abordo, tanto o das audiências criminais quanto o das normativas. Neles os termos utilizados são, em sua maioria, "estrangeiras" ou "migrantes" (com especificações como "imigrante", "solicitante", "pessoa em situação de refúgio", "pessoa em situação de asilo", "apátrida", entre outros) e que denotam categorias jurídicas específicas. Autoras do campo da criminologia das mobilidades utilizam termos como "non-citizen" (PICKERING; BOSWORTH; AAS, 2015) ou "foreign-national" (BOSWORTH, 2011).

4. No mestrado que desenvolvo, busco compreender como agentes e instâncias de diferentes aparelhos de Estado compreendem e constroem categorias judiciais e migratórias, as quais produzem e são produzidas por atributos de gênero, raça, classe e nacionalidade.

5. Uma Portaria é um ato administrativo elaborado pelo Poder Executivo que versa sobre a aplicação de leis e regulamentos ou ainda sobre a execução de serviços.

6. Como define o Ministério da Justiça, as medidas compulsórias são modalidades de retirada forçada do "estrangeiro" do Território Nacional. Os tipos de medida compulsória são a expulsão, a deportação e a repatriação. A expulsão é uma medida administrativa de retirada compulsória direcionada ao "imigrante ou [...] visitante com sentença condenatória transitada em julgado pela prática de crime de genocídio, crime contra a humanidade, crime de guerra, crime de agressão, crime comum doloso passível de pena privativa de liberdade, consideradas a gravidade e as possibilidades de ressocialização no território nacional". A repatriação ocorre quando o estrangeiro for impedido de ingressar no território brasileiro pela fiscalização da fronteira, no caso de a pessoa não ter documentos válidos ou visto. A deportação será aplicada para o estrangeiro que tiver entrada ou estada irregular no Brasil. Disponível em: Disponível em: $<$ https://www.justica.gov.br/seus-direitos/migracoes1/medidas-compulsorias $>$. Acesso em: 2 dez. 2020.

Há ainda a medida de extradição, que ocorre quando um Estado entrega um indivíduo acusado de cometer um crime ou condenado por um crime para que a justiça de outro Estado realize seu julgamento ou execute sua punição.

7. Utilizo o termo "em conflito com a lei" para indicar pessoas que têm sua trajetória de vida atravessada pela justiça criminal. Mais frequentemente, isso significa pessoas com processos criminais em andamento ou em cumprimento de pena. Por compreender que o atravessamento da vida pela justiça criminal não acontece de modo pontual somente no decorrer do processo criminal, o termo incluirá também pessoas com antecedentes penais. Para fins explicativos, no caso de se tratar de pessoas com processo criminal já terminado, isso será especificado no texto. 
8. Logo em 1818, decretos de D. João VI e o Tratado de Colonização apontam o interesse em "novos habitantes 'afetos aos diversos gêneros de trabalho"' (SEYFERTH 2008, p. 4), sendo incentivada aquilo que a autora chama de "colonização" de territórios brasileiros por famílias europeias, a quem são concedidas pelo rei pequenas propriedades. É na década de 1840 que a autora aponta a primeira aparição da categoria imigrante no campo político, "no momento de consolidação do Estado brasileiro" (SEYFERTH 2008, p. 4), quando estavam em jogo, além do povoamento do território, a necessidade de mão de obra. Ainda assim, Seyferth coloca que a abertura dos portos em 1808 já permitiu a entrada de "estrangeiros" e "sua fixação em algumas cidades portuárias, engajadas em atividades comerciais" (SEYFERTH 2008, p. 4), mas aponta como marco inicial da imigração no Brasil a fundação da colônia de Nova Friburgo (RJ) em 1819.

9. A autora aponta que em meados da década de 1850 acontece uma intensificação da migração, que é acompanhada do surgimento de demandas dos "colonos estrangeiros", como nomeia Seyferth, como liberdade religiosa e acesso a direitos civis. $\mathrm{O}$ afastamento da ideia do colono estrangeiro submisso vem acompanhado da construção do estrangeiro "indesejado, politizado, problemático, desqualificado como 'comunista", que emigrava "por motivos políticos" e entrava no país “disfarçado de agricultor” (SEYFERTH, 2008, p. 8).

10. Um Decreto é um ato administrativo promulgado por chefes dos poderes executivos - presidenta(e), governadoras(es) e prefeitas(os). Ele serve para regulamentar ou para possibilitar a execução da lei, não podendo ir contra ou além dela.

11. Disponível em: <https://www2.camara.leg.br/legin/fed/decret/1824-1899/ decreto-528-28-junho-1890-506935-norma-pe.html>. Acesso em: 02 dez. 2020. 12. Interessante notar aqui quando a autora aponta que poucas vezes a legislação estabeleceu critérios raciais de exclusão (SEYFERTH, 2008, p. 2), mas a eugenia se mostrava em critérios de saúde e higiene, por exemplo. Ela aponta como a questão racial surge na segunda metade do século XIX com as restrições à imigração chinesa, tida como decadente e marcada pela presença do ópio, e à imigração africana, "cuja vinda seria equivalente ao restabelecimento do tráfico de escravos" (SEYFERTH, 2008, p. 9). A seleção da imigração europeia se dava, por sua vez, por critérios "profissionais, morais, etários e de saúde" (SEYFERTH, 2008, p. 8). É, no entanto, interessante questionar de que formas tais critérios estabeleciam recortes de classe, raça, gênero, sexualidade e mesmo nacionalidade dentre europeus.

13. Disponível em: <https://www2.camara.leg.br/legin/fed/decret/1900-1909/ decreto-6455-19-abril-1907-502417-publicacaooriginal-1-pe.html>. Acesso em: 2 dez. 2020.

14. Disponível em: <https://www2.camara.leg.br/legin/fed/decret/1910-1919/ decreto-9081-3-novembro-1911-523578-republicacao-102836-pe.html>. Acesso em: 2 dez. 2020.

15. Disponível em: <https://www2.camara.leg.br/legin/fed/decret/1920-1929/ decreto-4247-6-janeiro-1921-568826-publicacaooriginal-92146-pl.html>. Acesso em: 2 dez. 2020.

16. Disponível em: <https://www2.camara.leg.br/legin/fed/decret/1920-1929/ decreto-4743-31-outubro-1923-567758-publicacaooriginal-91090-pl.html>. Acesso em: 2 dez. 2020. 
17. Um Decreto-Lei é um decreto com força de lei.

18. Disponível em: <https://www2.camara.leg.br/legin/fed/declei/1930-1939/ decreto-lei-406-4-maio-1938-348724-publicacaooriginal-1-pe.html>. Acesso em: 2 dez. 2020.

19. Disponível em: <https://www2.camara.leg.br/legin/fed/declei/1960-1969/ decreto-lei-417-10-janeiro-1969-378081-publicacaooriginal-1-pe.html>. Acesso em: 2 dez. 2020.

20. Disponível em: <http://www.planalto.gov.br/ccivil_03/LEIS/L6815.htm>. Acesso em: 2 dez. 2020.

21. O protocolo era o documento provisório que as pessoas migrantes recebiam ao entrar com processo de regularização migratória. Antes de receber o antigo Registro Nacional de Estrangeiro, documento migratório permanente, a Polícia Federal emitia o protocolo, que era então o principal documento de identificação em território nacional. Esse documento consistia em um quarto de folha sulfite A4 com uma foto da pessoa solicitante, um carimbo da Polícia Federal e informações como nome, data de nascimento, local de nascimento, sexo, data de entrada, tipo de pedido de visto e data de validade do protocolo. As condições precárias desse documento eram tema recorrente das pessoas migrantes, sendo inclusive tema de Audiências Públicas.

22. É especialmente interessante olhar para a justificativa acionada no veto do trecho que possibilitava a revogação da expulsão no caso de a pessoa já ter vivido no Brasil por mais de quatro anos antes da condenação penal. Consta como justificativa que "além de esvaziar a discricionariedade do Estado para gestão de sua política migratória, o dispositivo inviabilizaria promover a expulsão e retirada do território nacional de pessoas condenadas por crimes graves, tão somente pelo fato de terem vivido mais de 4 anos no país ao tempo do cometimento do delito". Disponível em: <http://www.planalto.gov.br/ccivil_03/_ ato2015-2018/2017/Msg/VEP-163.htm>. Acesso em: 2 dez. 2020.

23. Disponível em: <https://www2.camara.leg.br/legin/fed/decret/2017/decreto-9199-20-novembro-2017-785772-publicacaooriginal-154263-pe.html>. Acesso em: 2 dez. 2020.

24. Disponível em: <http://www.aba.abant.org.br/files/20171207_5a2959080b0a4.pdf>. Acesso em: 2 dez. 2020.

25. A Procuradora ou o Procurador-geral da República é nomeada(o) pela Presidência da República, passando por aprovação posterior da maioria absoluta do Senado. Ao cargo é atribuída a chefia do Ministério Público Federal (MPF), a função de procuradoria-geral eleitoral e a presidência do Conselho Nacional do Ministério Público. Exercendo funções de Ministério Público, deve ser sempre ouvida em processos do Supremo Tribunal Federal e Superior Tribunal de Justiça. Como consta no portal do MPF, pode ainda propor ações de inconstitucionalidade, representar para intervenção federal nos estados, propor ações penais e cíveis, propor a federalização de casos de crimes contra os direitos humanos no STJ, promover Ações Diretas de Inconstitucionalidade e ações penais para denunciar autoridades federais. A então procuradora, Raquel Dodge foi nomeada para o cargo de Procuradora-Geral da República por Michel Temer em 2017, terminando seu mandato de dois anos e deixando o cargo em setembro de 2019. Dodge foi substituída por Augusto Aras, nomeado por Jair Bolsonaro.

26. Para nomear algumas delas: Declaração Universal dos Direitos Humanos (1948) e Convenção Americana de Direitos Humanos (1969). 
27. A atualmente vigente Lei de Migração define que é possível autorizar residência "ao imigrante, ao residente fronteiriço ou ao visitante" que "esteja em liberdade provisória ou em cumprimento de pena no Brasil", ainda que vete a autorização de residência para "pessoa condenada criminalmente no Brasil ou no exterior por sentença transitada em julgado", salvo em casos de "infração menor potencial ofensivo", de pedido de residência por motivos de tratamento de saúde, acolhida humanitária e reunião familiar ou caso a pessoa seja beneficiária de tratado em matéria de residência e livre circulação (Art. 30). A Lei prevê ainda o cancelamento do documento no caso de expulsão, que ocorre nos casos de condenação com sentença transitada em julgado por "crime de genocídio, crime contra a humanidade, crime de guerra, crime de agressão", "crime comum doloso passível de pena privativa de liberdade, consideradas a gravidade e as possibilidades de ressocialização em território nacional" (Art. 54). A medida, por outro lado, é vetada nos casos em que "o expulsando tiver filho brasileiro que esteja sob sua guarda ou dependência econômica ou socioafetiva ou tiver pessoa brasileira sob sua tutela, tiver cônjuge ou companheiro residente no Brasil, sem discriminação alguma, reconhecido judicial ou legalmente, tiver ingressado no Brasil até os doze anos de idade, residindo desde então no País, ou for pessoa com mais de setenta anos que resida no País há mais de 10 (dez) anos, considerados a gravidade e o fundamento da expulsão" (Art. 55) (BRASIL, 2017b).

28. Sobre esse ponto, Viviane Balbuglio aponta que a Lei 13.257/2016, conhecida como Marco Legal de Atenção à Primeira Infância, equipara homens e mulheres na possibilidade de acesso à prisão domiciliar para responsáveis por filhas(os) de até 12 anos, imprescindíveis aos cuidados especiais de pessoa menor de seis anos ou com deficiência (BALBUGLIO, 2016, p. 27). Anteriormente, no Código de Processo Penal a possibilidade de prisão domiciliar era restrita às mães. Balbuglio aponta, contudo, que a mesma normativa viabiliza a prisão domiciliar em razão da paternidade para o pai que seja o único responsável pelos cuidados da(o) filha(o), condição que não é demandada das mães. Existem ainda outros requisitos a serem analisados como o de endereço fixo, que se mostra um obstáculo para quem não possui endereço fixo (BALBUGLIO, 2016, p. 32), como é o caso de grande parte de pessoas não-brasileiras presas no Brasil, e o de imprescindibilidade aos cuidados da(o) filha(o) ou dependente, critério de caráter subjetivo (BALBUGLIO, 2016, p. 31). No caso dessa audiência, como de outras que presenciei, é entendimento do juiz que o fato de a mãe ter viajado sem a(o) filha(o) já atesta sua prescindibilidade no cuidado dela(e). 29. O texto da Portaria 666 foi transformado no Projeto de Lei 5.326/19, de autoria do deputado José Medeiros (Podemos-MT). Apresentado em 02 de outubro de 2019 e atualmente em tramitação, o texto aguarda parecer do Relator na Comissão de Direitos Humanos e Minorias da Câmara dos Deputados (BRASIL, 2019a).

30. Também Isadora Lins França, analisando a produção da categoria "refugiados LGBTI", investiga como agências internacionais do mundo institucional do refúgio têm reconhecido a possibilidade de solicitação do reconhecimento do status de refugiado com base na orientação sexual e identidade de gênero (França, 2017). São examinadas as relações entre gênero, sexualidade e violência na produção de narrativas por diversos atores relacionados ao mundo institucional do refúgio, bem como pelos próprios solicitantes de refúgio. Nesse 
processo, a autora destaca as ambiguidades entre proteção e criminalização. Os processos que operam a transformação de "criminoso" em "vítima", de "migrante" em "refugiado", de "violência comum" em "grave violação de direitos", de "discriminação" em "perseguição", todas categorias que delimitam o campo de ação do aparato humanitário na forma do refúgio, obedecem a mecanismos que têm nas narrativas um dispositivo central, ainda que não se resumam a elas. Importa não só narrar, mas também a maneira como se narra, como se inscreve nas falas de refugiados e também nas dos agentes das instituições envolvidas com o refúgio a tortura, o assassinato, a violência sexual, a mutilação, a morte ou outras formas de violência. É dessa forma que vai sendo construída a legitimidade das histórias por diferentes agentes e estruturas administrativas, definindo quem pode ser reconhecido como uma história legítima de refúgio. 31. Eduardo Domenech mostra como alguns grupos sociais específicos foram "objeto de proibição, perseguição, detenção e deportação durante os anos das 'grandes migrações"' na América do Sul (DOMENECH, 2015, p. 26), tais como pessoas de nacionalidade chinesa e anarquistas. Marcia Sprandel traz ainda como a implementação da agenda antitráfico teve como impacto direto nos deslocamentos de trabalhadoras sexuais (SPRANDEL, 2015, p. 163).

\section{BIBLIOGRAFIA}

BALBUGLIO, Viviane. Sobre punição, lares e meias liberdades: um estudo do confinamento domiciliar de mulheres migrantes na cidade de São Paulo. 2016. 216 f. (Trabalho de Conclusão de Curso) - Faculdade de Direito de São Bernardo do Campo, 2016.

BOSWORTH, Mary. Deportation, detention and foreign-national prisoners in England and Wales. Citizenship Studies, v. 15, n. 5, p. 583-595, 2011.

BRASIL. Câmara dos Deputados. Projeto de Lei 5326/19. Altera a Lei no 13.445, de 2017, que institui a Lei de Migração. Brasília, 2019a. Disponível em: <https://www.camara.leg.br/proposicoesWeb/fichadetramitacao?idProposicao=2222905 > . Acesso em: $01 \mathrm{dez} .2020$.

BRASIL. Decreto-Lei n. 314, de 13 de março de 1967. Define os crimes contra a segurança nacional, a ordem política e social e dá outras providências. Brasília, 1967. Disponível em: <http://www.planalto.gov.br/ccivil_03/decreto-lei/1965-1988/Del0314.htm>. Acesso em: 01 dez. 2020.

BRASIL. Decreto-Lei 941, de 13 de outubro de 1969. Define a situação jurídica do estrangeiro no Brasil, e dá providências. Brasília, 1969. Disponível em: <https://www2.camara.leg.br/legin/fed/declei/1960-1969/ decreto-lei-941-13-outubro-1969-375371-publicacaooriginal-1-pe. html>. Acesso em: 01 dez. 2020.

BRASIL. Decreto 9.199, de 20 de novembro 2017. Regulamenta a Lei $\mathrm{n}^{\circ}$ 13.445, de 24 de maio de 2017, que institui a Lei de Migração. Brasília, 2017a. BRASIL. Lei 13.445, de 24 de maio de 2017. Institui a Lei da Migração. Brasília, 2017b. Disponível em: <https://www.justica.gov.br/seus-direitos/migracoes1/medidas-compulsorias $>$. Acesso em: 28 nov. 2020. 
BRASIL. Lei 9.474, de 22 de julho de 1997. Define mecanismos para a implementação do Estatuto dos Refugiados de 1951, e determina outras providências. Brasília, 1997. Disponível em: <http://www.planalto.gov. br/ccivil_03/leis/19474.htm>. Acesso em: 28 nov. 2020.

BRASIL. Ministério da Justiça e Segurança Pública. Departamento de Justiça, Classificação, Títulos e Qualificação. Portaria 6, de 30 de janeiro de 2015. Brasília, 2015. Disponível em: <http://pesquisa. in.gov.br/imprensa/jsp/visualiza/index.jsp?jornal=1 \&pagina $=41 \& d a-$ ta $=02 / 02 / 2015>$. Acesso em: 28 nov. 2020.

BRASIL. Ministério da Justiça e Segurança Pública. Departamento Penitenciário Nacional. Infopen. Levantamento Nacional de Informações Penitenciárias Atualização - Junho de 2017. Brasília, 2017c. Disponível em: <http://antigo.depen.gov.br/DEPEN/depen/sisdepen/infopen/relatorios-sinteticos/infopen-jun-2017-rev-12072019-0721. >. Acesso em: 01 dez. 2020.

BRASIL. Ministério da Justiça e Segurança Pública. Portaria n. 666, de 25 de julho de 2019. Dispõe sobre o impedimento de ingresso, a repatriação e a deportação sumária de pessoa perigosa ou que tenha praticado ato contrário aos princípios e objetivos dispostos na Constituição Federal. Diário Oficial da União: seção 1, Brasília, p. 166, 26 jul. 2019b. Disponível em: <https://www.in.gov.br/en/web/dou/-/portaria-n-666-de-25-de-julho-de-2019-207244569>. Acesso em: 28 nov. 2020. BRASIL. Ministério da Justiça e Segurança Pública. Portaria n. 770, de 11 de outubro 2019. Dispõe sobre o impedimento de ingresso, a repatriação e a deportação de pessoa perigosa ou que tenha praticado ato contrário aos princípios e objetivos dispostos na Constituição Federal. Diário Oficial da União: seção 1, Brasília, p. 34, 14 out. 2019c. Disponível em: <http://www.in.gov.br/en/web/dou/-/portaria-n-770-de-11-de-outubro-de-2019-221565769>. Acesso em: 01 dez. 2020.

BRASIL. Ministério Público Federal. Procuradoria-Geral da República. Arguição de Descumprimento de Preceito Fundamental contra a Portaria 666. Brasília, 2020. Disponível em: < http://www.mpf.mp.br/pgr/documentos/ADPF666.pdf.> . Acesso: 28 nov. 2020.

BUMACHAR, Bruna Louzada. Nem dentro, nem fora: a experiência prisional de estrangeiras em São Paulo. 2016. Tese (Doutorado em Antropologia Social) - Universidade de Campinas, 2016.

DOMENECH, Eduardo. O controle da imigração “indesejável”: expulsão e expulsabilidade na América do Sul. Ciência e Cultura, v. 67, n. 2, 2015.

FACUNDO NAVIA, Angela. Êxodos e refúgios: colombianos refugiados no Sul e Sudeste do Brasil. 388 f. 2014. Tese (Doutorado em Antropologia Social) - UFRJ/Museu Nacional/PPGAS, 2014.

FRANÇA, Isadora Lins. Refugiados LGBTI: direitos e narrativas entrecruzando gênero, sexualidade e violência. Cadernos Pagu, n. 50, 2017. Disponível em: <https://periodicos.sbu.unicamp.br/ojs/index.php/cadpagu/article/view/8650723>. Acesso em: 2 dez. 2020. 
GLICK SCHILLER, Nina; SALAZAR, Noel B. Regimes of Mobility Across the Globe. Journal of Ethnic and Migration Studies, 2012.

HARTMANN, Érica de Oliveira; BORGES, Guilherme Roman; ARAÚJO, Jorge Alberto A. de. Tráfico Internacional de Entorpecentes: o fluxo no maior aeroporto internacional do Brasil - Aeroporto de Guarulhos. Curitiba: IFDDH, 2016.

HASTINGS, Donnan; THOMAS, Wilson. Body Politics. In: HASTINGS, Donnan; THOMAS, Wilson. Borders: Frontiers of Identity, Nation and State. New York: Berg, 1999.

JEGANATHAN, Pradeep. Border, checkpoint, bodies. In: HORSTMANN, Alexander; SAXER, Martin; RIPPA, Alessandro (Eds.). Routledge Handbook of Asia’s Borderlands. Abingdon: Routledge, 2018.

MORAES, Ana Luisa Zago de. Crimigração: a relação entre política migratória e política criminal no Brasil. 2016. 374 f. Tese (Doutorado em Ciências Criminais) - Faculdade de Direito da Pontifícia Universidade Católica do Rio Grande do Sul, Porto Alegre, 2016.

PADOVANI, Natália Corazza. Sobre casos e casamentos: Afetos e "amores” através de penitenciárias femininas em São Paulo e Barcelona. 2015. 368 f. Tese (Doutorado em Antropologia Social) - Universidade de Campinas, 2015.

PICKERING, S. J., BOSWORTH, M.; AAS, K. F. The criminology of mobility. In: PICKERING, S. J.; HAM, J. (Eds.). The Routledge Handbook on Crime and International Migration. 1. ed. Abingdon: Routledge, 2015. p. 382-395.

SEYFERTH, Giralda. Imigrantes, estrangeiros: a trajetória de uma categoria incomoda no campo político. Trabalho apresentado na Mesa-Redonda Imigrantes e Emigrantes: as transformações das relações do Estado Brasileiro com a Migração. 26 Re Reunião Brasileira DE ANtropologia, realizada entre os dias 01 e 04 de junho de 2008, Porto Seguro, Brasil.

SPRANDEL, Márcia. Migração e crime: a Lei 6.815, de 1980. REMHU, ano XXIII, n. 45, p. 145-168, 2015.

VIANNA, Adriana; LOWENKRON, Laura. O duplo fazer do gênero e do Estado: interconexões, materialidades e linguagens. Cadernos Pagu, n. 51, 2017. Disponível em: < https://periodicos.sbu.unicamp.br/ojs/index.php/cadpagu/issue/view/>. Acesso em: 28 nov. 2010. 